The $B D J$ News section accepts items that include general news, latest research and diary events that interest our readers.

Press releases or articles may be edited, and should include a colour photograph if possible. Please direct your correspondence to the News Editor, Arveen Bajaj at the BDJ, The Macmillan Building, 4 Crinan Street, London N1 9XW or by email to bdj@bda.org

\section{Police request dentists help to identify body}

Lancashire Police are requesting help from dentists to identify the body of a person found in woodland near Lancaster in November 2006. The individual, believed to be male, had been dead for several months and efforts so far to identify him or her have proved unsuccessful.

The condition of the individual was such that few physical features could be ascertained, other than they were approximately $6 \mathrm{ft}$ tall and had size 11 feet. Believed to be between 20 and 50 years of age, it is possible that they may have had some connections with Ontario, Canada.

An examination of the teeth however revealed some clues that police are anxious for help with, with two distinguishable areas of potential identification. There is a $2 \mathrm{~mm}$ midline diastema in the maxilla and also ongoing crown work, as the body has an excellent root filling with the crown not yet restored or filled with amalgam. The individual is believed to have had a large mouth and to have looked after their teeth.

Anyone who has any information that may help to identify this individual is asked to contact Lancaster Police on 01524 63333, quoting log reference 128nq/051106 or e-mail Detective Chief Inspector Neil Esseen at neil. esseen@lancashire.pnn.police.uk.

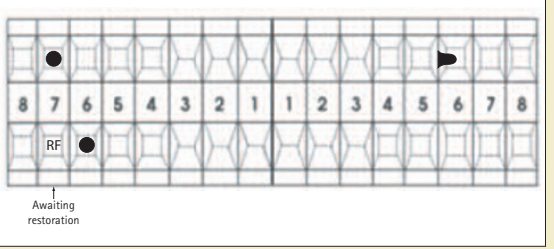

A copy of the individual's dental chart

\title{
No mountain high enough
}

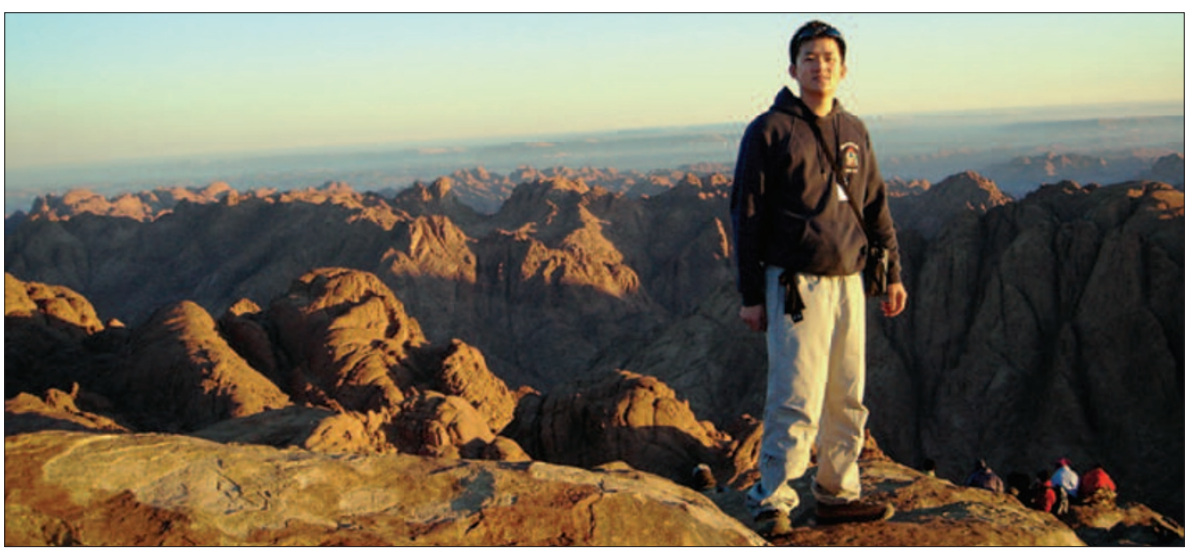

Billy Chan, a dentist from Swansea completed the Sinai Trek for Dentaid in 2005.

The oral health charity Dentaid is offering members of the dental profession, dental trade, and the general public the opportunity to conquer Mount Sinai, visit the Pyramids and trek through part of the Sahara - one of the most varied and beautiful desert landscapes in the world.

The Charity Trek, which takes place from 25 Nov - 1 Dec 2007, will raise vital funds for Dentaid's pioneering work improving oral health for disadvantaged communities around the world. The challenge event follows on from Dentaid's Italy trek climbing the three active volcanoes of Vesuvius, Stromboli and Etna in 2006. Chief Executive Luke Wordley said, "This year we wanted to take our supporters somewhere more exotic, and offer experiences even more out of the ordinary!" The trip's highlights include visiting the Pyramids at Giza - one of the Seven Wonders of the Ancient World, climbing Mount Sinai - where Moses is believed to have received the Ten Commandments and encountering the grandeur and beauty of the Sinai landscape, and camping out in Bedouin tents or even underneath the stars of the pristine desert sky. On the last day there is also a chance to relax on the shores of the Red Sea.

Those who would like to take part must raise a minimum of $£ 1,980$, of which at least $£ 1,000$ goes to Dentaid after tour costs. However, Fundraising Assistant Dafydd Pierce is determined that no one should be put off by this aspect of the challenge. Almost 100 people have successfully taken part in Challenge Events for Dentaid in the past and with the charity's support, advice and ideas, past trekkers have regularly exceeded their fundraising goals with ease. In order to take part in the trek please call 01794324249 for an application pack or info@dentaid.org. For further information about Dentaid please visit www.dentaid.org.

\section{Oral health for dementia sufferers}

The British Society of Gerodontology (BSG) and the British Society for Disability and Oral Health recently launched guidelines for the Development of Local Standards of Oral Health Care for People with Dementia, at the BSG winter scientific meeting, 2006.

Funded by the Department of Health, the document aims to assist in the development of local standards for oral health care for people with dementia.

The organisations state that as the number of older people increases and the incidence of dementia rises, more dental teams will encounter the oral care problems of people with this disorder. For further information please visit www.gerodontology.com. 


\section{Integrating
prevention}

Dental clinicians and their educators report a lack of self-confidence either in applying or teaching tobacco use prevention and cessation, according to the Oral Health Network on Tobacco Use Prevention and Cessation (OHNTPC).

Additionally, a number of barriers to tobacco use cessation such as underdeveloped professional experience, time constraints for education and lack of financial compensation need to be removed or mitigated, it says.

The organisation says these issues may be solved more efficiently with joint efforts using a network of public health and health professionals of dentistry and dental hygiene.

The Network was developed to support a global collaborative forum to establish and augment national and international expertise in areas including assisting oral health professionals to implement tobacco use prevention and cessation in the daily practice and integrating tobacco use prevention and cessation into dental and dental hygiene education.

\section{Orthodontic}

\section{poster success}

The Orthodontic Department at Seacroft Hospital in Leeds are celebrating national recognition of their clinical research endeavours with an award at the recent 2006 British Orthodontic Conference (BOC) in Edinburgh.

Consultant Orthodontist and Trainer David Morris, and Nichola Price, exSenior Registrar in Orthodontics, were awarded first prize (sponsored by Hawley Russell) for their clinical poster presentation last month.

The poster was based on their completed randomised controlled clinical trial that compared the efficacy of bonding orthodontic brackets with either composite resin or a newly marketed reinforced glass ionomer cement. This original research project has been carried out at Seacroft Hospital over the past three years.

The winning poster was chosen by a panel of judges from a total of over 50 posters presented during the Conference. This latest success follows on from the third place BOC poster prize won by the Seacroft Orthodontic Department back in 2004 along with more recent national awards gained in the last two consecutive years for the quality of treated cases presented by Seacroft-trained specialist registrars.

This is the second time that David Morris has been awarded the main poster prize at the British Orthodontic Conference, having won it for the first time in 1997. Both winners have donated their poster prize money to the Tuberous Sclerosis Association (www.tuberous-sclerosis.org).

found to have a high degree of genomic alterations. A correlation between tumour aggressiveness could be found for a specific set of 5 loci. Three stroma-specific loci were associated with tumour size and regional nodal (small mass) metastases. Also, two specific genomic alterations (markers termed "hot spots") were positively correlated with node metastases and clinical stage.

"Stroma-specific genetic alterations are associated with smoking-related head and neck SCC genesis," the authors write. "We hope that our genomic observations, which point to genomic regions that may harbor many genes, will guide future in-depth functional and mechanistic studies. Nevertheless, our current observations can be used to identify new biomarkers for prediction of clinical outcome and potentially novel compartments for targeted therapy and prevention."

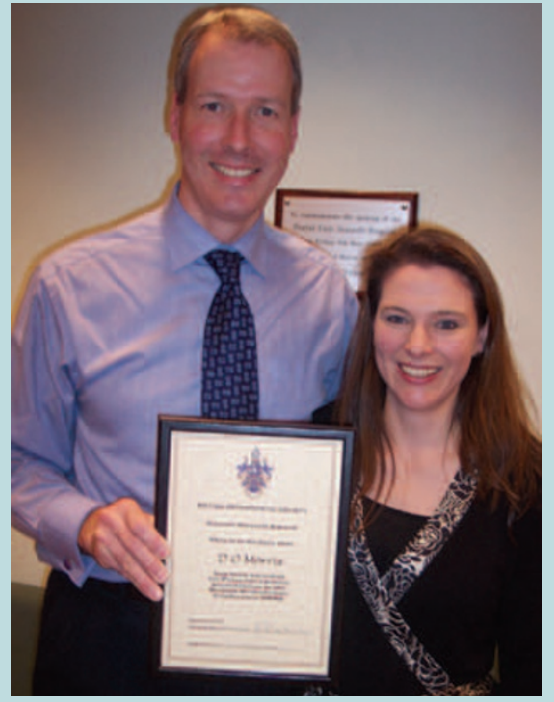

David Morris and Nichola Price with their 1st Prize certificate from the recent 2006 British Orthodontic Conference and neck SCC from smokers were 


\section{Calcium important for nursing mothers' oral health}

Mothers who breastfeed should be sure to have enough calcium in their diet, or may risk bone loss around their teeth and gums, according to a new study that appears in the January issue of the Journal of Periodontology.

Researchers from Tohoku University in Japan investigated if lactation affects alveolar bone loss in rat models of experimental periodontitis. They found mothers who are lactating could put the bone structures around their teeth at risk, especially when there was not enough calcium in their diet. "Our research emphasised the importance of having a high-calcium diet while breast-feeding," said Dr Kanako Shoji, Division of Periodontology and Endod- ontology at Tohoku University.

"While our study was on a rat population, the evidence confirmed that breastfeeding can cause increased bone loss in the mother, especially when the mother has insufficient calcium intake. But additional studies in human populations are necessary to confirm these findings."

The study showed that all groups with insufficient calcium intake saw an acute inflammatory reaction in periodontal tissues and disruption of the gingival epithelium, in addition to increased attachment loss, and increased alveolar bone loss. Those groups which were lactating saw even greater attachment loss and bone loss.

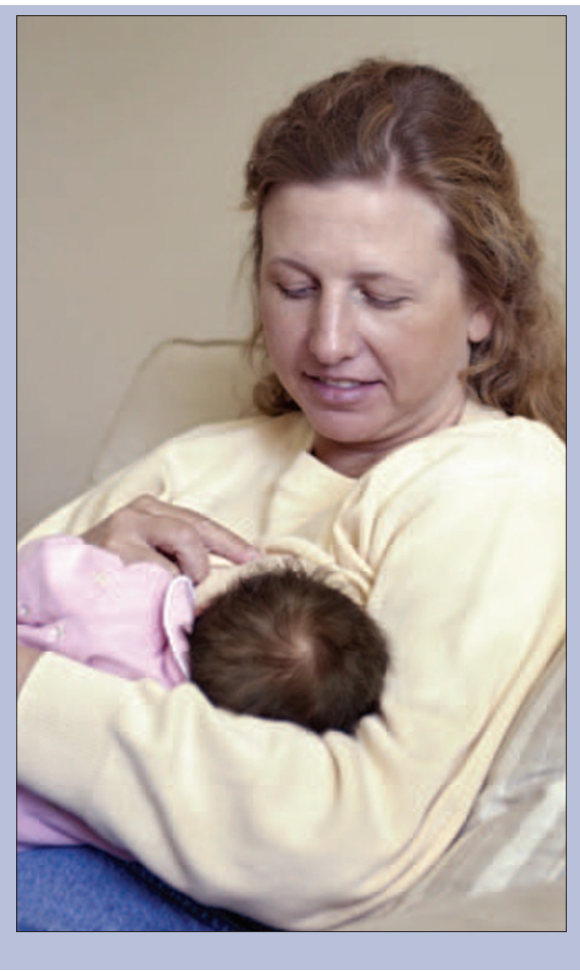

\section{Dentists could detect osteoporosis}

Researchers in the School of Dentistry at The University of Manchester have created a unique way of identifying osteoporosis sufferers from ordinary dental radiographs.

Professor Keith Horner and Dr Hugh Devlin co-ordinated a three year, EUfunded collaboration with the Universities of Athens, Leuven, Amsterdam and Malmo, to develop the largely automated approach to detecting the disease. Their findings are published online by the journal Bone.

The team has developed a revolutionary, software-based approach to detecting osteoporosis during routine dental X-rays, by automatically measuring the thickness of part of the patient's lower jaw.

X-rays are used widely in the NHS to examine wisdom teeth, gum disease and during general check-ups, and

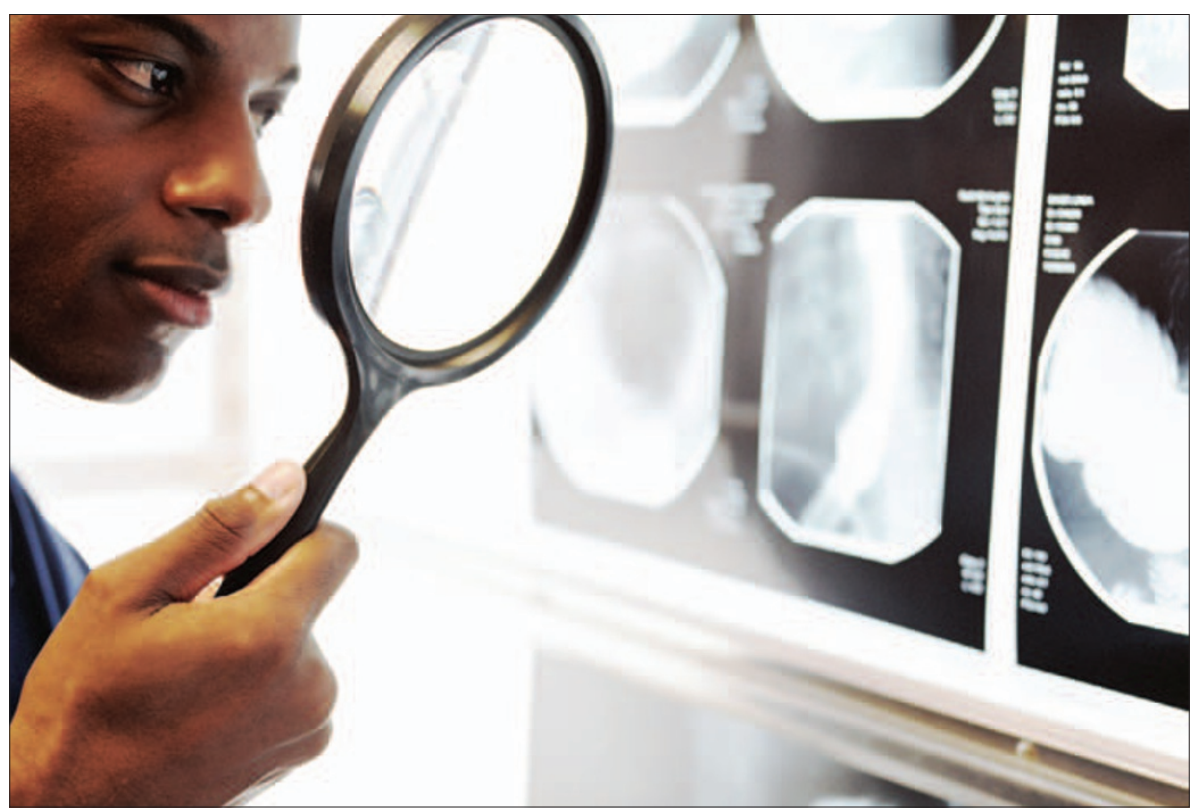

Researchers can use dental radiographs to identify osteoporosis sufferers their use is on the rise. To harness these high usage-rates, the team has drawn on 'active shape modeling' technology developed by the University's Division of Imaging Sciences to automatically detect jaw cortex widths of less than $3 \mathrm{~mm}-\mathrm{a}$ key indicator of osteoporosis - during the $\mathrm{X}$-ray process, and alert the dentist.

Professor Horner explained, "At the start of our study we tested 652 women for osteoporosis using the current 'gold standard', and highly expensive, DXA test. This identified 140 sufferers. Our automated X-ray test immediately flagged-up over half of these. The patients concerned may not otherwise have been tested for osteoporosis, and in a real-life situation would immediately be referred for conclusive DXA testing."

He added that this cheap, simple and largely-automated approach could be carried out by every dentist taking routine $\mathrm{X}$ rays, and the success rate was as good as having a specialist consultant on hand.

Dr Devlin continued, "As well as being virtually no extra work for the dentist, the diagnosis does not depend on patients being aware that they are at risk of the disease. Just by introducing a simple tool and getting healthcare professionals working together, around two in five sufferers undertaking routine dental Xrays could be identified."

The team say that the next stage will be for an X-ray equipment company to integrate the software with its products, and once available to dentists it is hoped that entire primary care trusts might opt in. 


\section{DIARY}

February

2007 Career opportunities in UK

Date: 9 February 2007

Venue: Hotel Russell, Russell Square, London

Tel: 02075634590

Email:events@bda.org

Moving to private practice -

conversion and beyond

Date: 23 February 2007

Venue: BDA, London

Tel: 02075634590

Email:events@bda.org

April

The Society of Manchester Dental Alumni (SOMANDA) biennial meeting and reunion Date: 20 April 2007

Venue: University of Manchester

Email: carolynstylianou@ntlworld.com

May

ADI 20th Anniversary Congress

Date: 3-5 May 2007

Venue: ICC in Birmingham

www.adi.org.uk

BDA British Dental Conference

and Exhibition 2007

Date: 24-26 May 2007

Venue: Harrogate International

Centre (HIC)

Tel: 02075634590

Email: events@bda.org

June

14th Annual Congress of the

Turkish Dental Association

Date: 11-17 June 2007

Venue: Lütfi Kirdar Convention Center,

Istanbul, Turkey

Email: tdbkongresi.com

www.tdbkongresi.com

\section{Teeth regenerated using stem cells}

A multi-national research team headed by University of Southern California School of Dentistry researcher Dr Songtao Shi, has successfully regenerated tooth root and supporting periodontal ligaments to restore tooth function in an animal model. The breakthrough holds significant promise for clinical application in human patients.

The study appeared last month in the inaugural issue of PLOS ONE. Utilising stem cells harvested from the extracted wisdom teeth of 18 to 20-year-olds, Dr Shi and colleagues created sufficient root and ligament structure to support a crown restoration in their animal model. The resulting tooth restoration closely resembled the original tooth in function and strength.

The technique relies on stem cells harvested from the root apical papilla, which is responsible for the development of a tooth's root and periodontal ligament. Previous studies conducted by Dr Shi and collaborator Stan Gronthos at the National Institutes of Health had utilised dental pulp stem cells. Dr Shi found the new technique to be superior.

"The apical papilla provides better stem cells for root structure regeneration. With this technique, the strength of the tooth restoration is not quite as strong as the original tooth, but we believe it is sufficient to withstand normal wear and tear," he said.

He hopes to move the technique to clinical trials within the next several years, a potential boon for dental patients who are not appropriate candidates for dental implant therapy or would prefer living tissue derived from

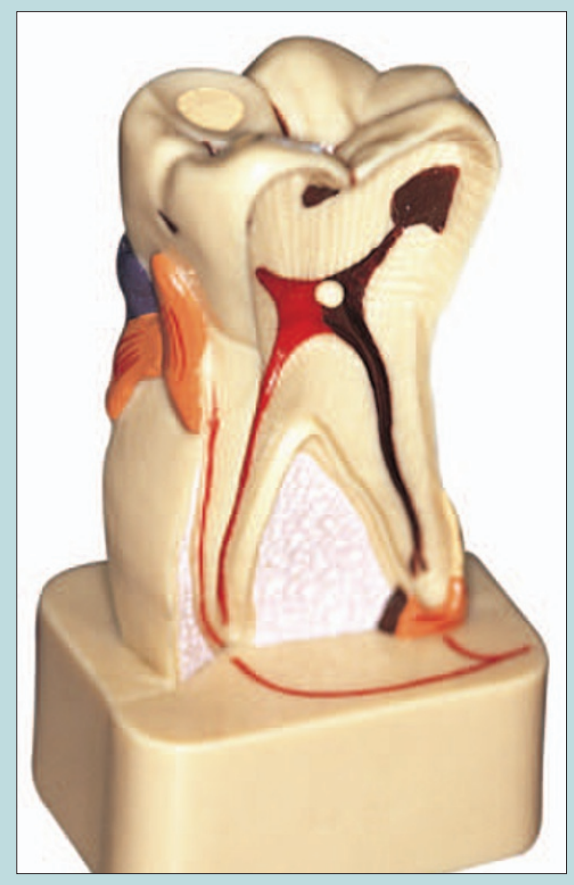

their own teeth. "Implant patients must have sufficient bone in the jaw to support the implant. For those who don't, this therapy would be a great alternative," said Dr Shi.

He believes that the not-so-distant future may be one in which not only wisdom teeth, but those baby teeth once left to the tooth fairy for a pittance, will become valuable therapeutic tools. "We will be able to provide not only this technique, but other new therapies utilising a patient's own stem cells harvested from their preserved teeth. This is a very exciting discovery and one that I hope to see in wide-spread clinical use in the near future."

\section{Students part of collaborative project}

Students from the School of Dentistry at The University of Manchester are helping transform the provision of dental care in less well-off areas of South Manchester.

A collaborative project between the University and Manchester Primary Care Trust is providing state-of-the-art surgeries, so that dental students can offer care to people living in Woodhouse Park in Wythenshawe.

The students will work alongside qualified dentists to provide a comprehensive range of treatments free of charge to resi- dents who are not under the care of an NHS dentist, on an appointment basis.

The outreach scheme will also help educate the budding dentists, who will work alongside qualified practitioners to gain experience of paediatric dentistry, orthodontics and restorative dental treatment.

Housed within the $£ 4.6$ million multifunctional Forum Health centre in Wythenshawe and opened by the Chief Dental Officer for England Barry Cockcroft, the centre will offer seven dental surgeries, an X-ray room and its own reception and waiting area. It is the largest in the coun- try within the Department of Health's NHS Local Improvement Finance Trust (LIFT) scheme - which aims to improve and develop frontline primary and community care facilities.

Professor Anthony Blinkhorn OBE, Outreach Director and one of the original team which developed the scheme, said: "Outreach teaching schemes play an important role in providing convenient and accessible NHS dental services to the community. They also give students valuable experience of working within the local area, which often encourages them to choose to practice locally once they have qualified." 


\section{Preventing caries in cleft lip/palate}

Patients with cleft conditions can prevent tooth decay by adopting oral hygiene strategies, according to a new study which provides strategies for early prevention.

The study says that children with cleft lip/palate face predisposing factors to acquiring dental tooth decay, and patients with cleft conditions generally display poorer oral hygiene and high susceptibility to caries, because of the difficulty in achieving adequate plaque control associated with dental anomalies and defects. Therefore, it is key that parents and their children with clefts learn and practice effective oral hygiene.

The study's researchers presented eight strategies for early prevention which include making contact with the dentist of the cleft lip/palate team who can encourage good feeding habits and general oral health, using chemotherapeutic products to clean intraoral appliances when removed from the mouth and having regular dental examinations every six months. Fluoride supplements in nonfluoridated areas are recommended.

The study claims that by beginning even before birth, patients with cleft lip/ palate can lessen the chance of dental caries by adopting the outlined strategies as preventive dental care is even more important in patients with cleft problems compared with patients without clefts. The study is published in the latest Cleft Palate Craniofacial Journal.

\section{Dentists can help patients fighting alcoholism}

Addiction experts at the Medical University of South Carolina (MUSC) say the link between oral cancer and heavy drinking makes dentists ideal sources of alcohol intervention.

The study, which appeared in the December 2006 issue of the Journal of the American Dental Association (JADA) also finds that most patients don't mind discussing alcohol use with their dentist.

"We thought alcohol was a sensitive topic, and that people might feel it's okay if their doctor talked to them about alcohol use, but not their dentist." said Peter M Miller, Professor of Psychiatry and Behavioral Sciences at MUSC.

MUSC researchers collected information from 408 adults. All were treated at an emergency walk-in dental clinic during a four-month period in 2005. Patients were asked questions about their drinking habits and their thoughts about having their dentist discuss alcohol use with them.

About 80 per cent of people in the study said that dentists should feel free to ask patients about their drinking habits and 25 per cent said they would be embarrassed if their dentist asked such a question. However, 90 per cent said they would give an honest answer. More than 90 per cent of the people in the study also agreed that if drinking were affecting their oral health, their dentist should advise them to reduce the amount they drink, or to quit.
The US National Institute on Alcohol Abuse and Alcoholism (NIAAA) estimates that nearly 50 per cent of cases of oropharyngeal cancer (OPC) are associated with heavy drinking. Miller said most people are not aware that heavy drinking is linked to oral cancer risk and, therefore, might wonder why a dentist would ask about drinking habits.

Professor Miller said that the results of the study showed that dentists should be trained in how to talk with patients about alcohol use. "We wouldn't expect the dentist to do counselling - just provide information," he said. "If someone looks like he has a problem, it's a matter of referral to either an alcoholism or addiction treatment centre, or a psychiatrist or psychologist."

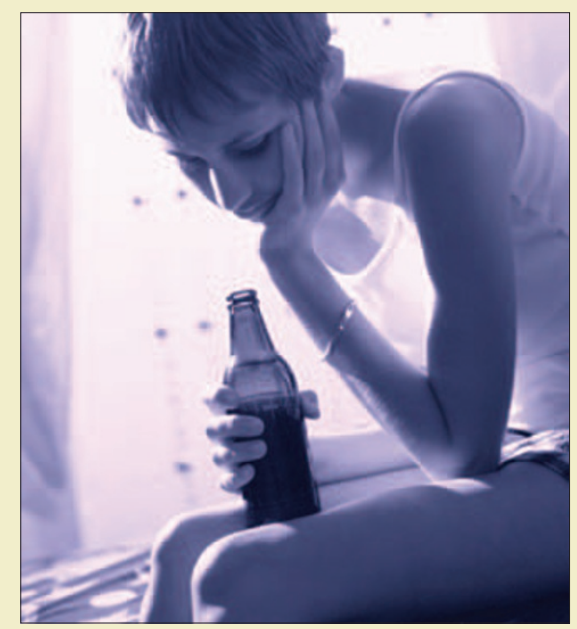

